conscientiously deny the advisability of doing all that lies in our power to counteract its influence, which may be so potent for evil. And it is here, I think, that the antiseptic treatment of wounds shows itself to manifest advantage, for when decomposition of the discharges is allowed to take place unchecked, how much more likely are we to get thrombosis extending beyond the immediate seat of injury, how much more likely in such cases to get rapid softening of the clot, and, as a natural consequence, detachment of emboli rife with mischief, by reason of their mechanical action, and still more so because they are saturated with septic matter. It is often a question of pyæmia or not-of life or death to the patient.

The two prominent features of thrombosis are: 1. Its causation. 2. The fate of the clot.

To gain some clue to an answer to the question, Why does the blood coagulate in the vessels ? let us consider the diseased states which are not unfrequently complicated with the untoward event. And firstly, because they will be fresh in the minds of many of you, I will give you the fatal cases that happened in our hospital during the past year. There were four of them. The index of the pathological reports runs practically as follows:-

No. 1. Female, aged thirty-eight.-Phthisis ; tubercular ulceration of intestines; perforation of cæcum; peri-cæcal abscess ; thrombosis of right common and external iliacs and femoral veins.

No. 2. Female, aged forty-six.-Fracture of ribs and pelvis; localised pleurisy; decolorised granular clot in right ventricle; embolism and subsequent thrombosis of pulmonary artery.

No. 3. Female, aged forty-three.-Primary thrombosis of iliac, femoral, and popliteal arteries and veins; gangrene of leg; bedsore ; recent infarction in liver.

No. 4. Female, aged sixty-three.-Cancer of cæcum perforation ; acute peritonitis ; phthisis ; thrombosis of left femoral and popliteal arteries and veins; gangrene of leg.

The third case, since the patient was apparently a healthy woman until the onset of the plugging, seems to point to the condition of the walls of the vessels as the immediate cause and the microscopical appearance of the internal coat of the arteries gave weight to that view, even if it did not establish its truth.

In the other three cases, you notet! st in two of them there was a combination of circumstan_es likely to lead to a vitiated state of blood: in one cancer and phthisis; in another phthisis and ulceration of the bowel, with abscess from perforation; whilst the remaining one falls into the same category, seeing that in it there was sudden diminution of bodily activity through confinement to bed from severe injury.

Amongst those that have come under my own obse' 'tion are the following :-

Thrombosis of cerebral veins in phthisis and in marasmus; of the basilic and other veins of the arm in septicrmia, from compound fracture of jaw, with cellulitis of forearm of pulmonary artery, fatal immediately after parturition ; of the varicose veins of the lower extremity; of axillary and femoral veins in post-parturient women; of the axillary vein in rheumatic fever; of the brachial artery from bruising. In textbooks you will find, amplifying the list: Plugging of the cerelral arteries in syphilis; capillary thrombosis as the starting-point of cancrum oris, and as the explanation of the multiple openings in carbuncle ; not forgetting those cases where coagulation is intentionally brought about, as in the ligation of arteries, and the operation for varicose veins. On analysing the foregoing, we arrive at the conclusion that there are two diseased conditions-one of the bloodvessels, the other of the blood,-which are so frequently seen as marked features in thrombosis that we are driven to accept that a causal relation exists between them. Slowing of the blood-current from weak action of the heart acts as a subsidiary factor.

In the first place, let me explain the different ways by which the blood may become so vitiated that its fluidity can no longer be maintained; and the simplest way of doing this is to make two groups: $(\alpha)$ that in which the fibrin factors are increased; and $(b)$ that in which excrementitious matter is in excess from defective elimination, as in gout, or abnormal material is introduced from without, as in septicamia.

The two groups are purely artificial, and are introduced rather for the sake of clearness of demonstration than for clinical accuracy. If it be admitted that the composition of the blood does play a very important part in its own coagulation, there remains for consideration the nature of the changes which directly underlie the phenomenon. The reasoning on this point, since we know of so few facts and still less of their correlation, is to a great extent speculative. Yet although this forbids our drawing any wide conclusions, there is sufficient that is probable to urge to further research and to some extent to indicate the line of action to be taken. Such questions as the following suggest themselves:-Is the chemical composition or constitution of the fibrin factors altered? If so, does this depend on a general physicochemical change of the constituents of the blood in which they are involved, or is there some definite yet subtle agency at work sufficing to effect the necessary means to the end? And supposing this to be the fact, what is the nature of that agency? Is it an altered mode of life of the white corpuscles by virtue of which they entail in their own changes the coagulation of the blood? We know that on watching the clotting process in liquor sanguinis obtained by subsidence, it is seen to commence by the formation of fine threads of fibrin in connexion with the leucocytes. Or, again, may not the conditions of these leucocytes be one of death rather than life, and that thus they count only as any other foreign matter? By most observers the former hypothesis is deemed the correct one; but Mr. Wharton Jones, one of the greatest of living authorities on the subject, looks upon the amceboid movements as the manifestations only of moribund corpuscles. Lastly, does not the whole question turn on the generation of a ferment, and thus place us on a less equivocal basis by relegating the condition to others of a similar nature tolerably well understood? The fact that coagulation of the blood is more likely to take place in such diseases as pyæmia, septicæmia, and the like, where minute organisms called micrococci have been found, lends weight to such a theory.

Since the above lines were written there has been a case in the hospital of acute necrosis of the clavicle, in a well. nourished girl aged fourteen years, coming on without apparent cause, and this was the sequence of events : acute periostitis and ostitis leading to necrosis, thrombosis of the common femoral vein, disintegration of the clot, embolism, and circumscribed metastatic abscesses in the lung; at no time was there a wound of any kind. This case illustrates two points in pathology : firstly, that the blood-poisoning may be developed without access of air to favour or account for the necessary decompositions-a proof, I think, that the most virulent pyæmia may depend entirely on the infective matter resulting from the inflammatory state ; and, secondly, that the change in the blood is sufficient to bring about its coagulation without appreciable disease in the walls of the containing vessel.

( $T$ o be concluded.)

\section{NOTES OF MILITARY SURGERY.}

\section{By Surgeon J. LEWTAS, M.B. LoND., GUIDES CAVALRY.}

A FEW notes of some of the injuries received in the cavalry affair near Futtehabad, Afghanistan, on April 2nd, may perhaps interest some of the readers of THE LANCET. The portion of the Guides Cavalry present on that occasion numbered about two hundred sabres, and our casualties were five killed and twenty-eight wounded.

CASE 1. Penetrating Gunshot Wound of Frontal Bone.The subject of this injury, a Sikh trooper, was hit by a stray bullet before the cavalry came into action. The bullet entered just above and to the right of the root of the nose. At the same time, also, the right eyeball projected prominently forwards, and was painful. He did not lose consciousness, but complained of pain in the head, and especially in the right eye. The eyeball was uninjured, but the conjunctiva was injected, and there was a small quantity of blood between the lids. He thought that the ball had passed out through the right orbit-a not impossible hypothesis, since bullets were coming across from our left, where the enemy were outflanking us. The subsequent history of the case, too, gave support for a while to his idea, for it seemed to indicate but slight injury to the brain. During the first eleven days the only symptoms were diffused headache and drowsiness, while there was dilatation 
of the right pupil and ptosis of the right upper cyelid, the two latter symptoms being not impossible results of an injury to the orbit only.

Suddenly, however, on the eleventh day, new symptoms developed themselves-viz., epileptiform convulsions followed by coma. The first fit occurred about midnight on April 13th. This passed off in half an hour, leaving a condition of extreme susceptibility to muscular spasm; so much so that the attempt to give him a drink brought on locking of the jaws, twitching of the facial muscles on the right side, and spasmodic movements of the limbs. About an hour later he had a second fit, and the convulsive stage of this was of such duration, and attended by such exhanstion-his body being bathed in perspiration and his pulse rapid beyond counting - that I resorted to chloroform-inhalation to bring on the stage of coma at once. A subcutaneous injection of one-sixth of a grain of morphia was given to him while under the influence of chloroform, and he then slept for four or five hours. The next day, April 14th, he had a third fit, which was similarly treated, and since then up to the present date, April 23rd, there has been no return. Dilatation of the right pupil and ptosis persist. There is, however, no squint; nor are any of the movements of the eyeball impaired. $\mathrm{He}$ is drowsy and somewhat irritable. There is also decided impairment of memory, as he no longer remembers the occurrences of that day, or even that he was wounded. There is still an abundant discharge of yellowishgreen pus from the opening in the frontal bone, and there is some prominence of the inner angle of the roof of the right orbit.

Remar7is.-The course and symptoms have not, I think, confirmed the opinion of the man himself that the ball escaped by way of the right orbit; the injury to the contents of the latter would have been greater, whereas the protrusion of the eyeball would be sufficiently accounted for by a depression of the roof of the orbit caused by the bullet in its passage backwards. There can, I think, be little donbt that the ball has lodged within the skull, but at what precise spot it is impossible to determine.

CASL 2. Gunshot Fracture of Great Trochanter of Femur; death on nineteenth day. - The bullet in this case entered at the outer side of the right thigh, about two inches below the great trochanter, passed upwards and inwards, splintering that projection, and finally lodged superficially over the base of the sicrum, where it pointed. Its position, however, was not so superficial that the bullet could be grasped between the finger and thumb; it gave rise rather to a diffused swelling, in which the exact position of the bullet was uncertain. Hence I did not feel justified in cutting into this prominence, but sent him as he was to the field hospital at Jelalabad, where a few days later the bullet worked towards the surface, and was extracted. The discharge from the track of the bullet was abundant and fetid; syringing the wound twice, and sometimes oftener, daily with carbolic lotion, and a free use of disinfecting powder (M'Dougall's), failed to keep down the fetor. He was further weakened by obstinate diarrhoea, over which treatment of various kinds had little effect. He died on April 20th, nineteen days after receiving the injury.

Remarks. - It is not the time yet to gather up the lessons upon gunshot fracture of the thigh derived from this war Five cases have now come under my notice, and they have all supported the received canons of military surgery; especially have they shown the advisability of immediate amputation in fractures of even the upper third if, as is invariably the case in hill warfare, the patient has to be carried many miles to a permanent hospital, for on arrival at the latter he is so exhausted by the journey, and the limb is so much swollen, that an amputation then performed has most unfavourable results. In saying this I have two cases in particular in my mind, both of them gunshot fractures of the upper half of the femur. One of these was carried from Ali Musjid to Jumrood, about ten miles; the other was carried for more than twelve hours in a dhooly, part of the time in darkness over rocks; and both of them died under the subsequent operation. The case of a man so injured is desperate, and justifies desperate measures: if, under the conditions supposed, his chance of life is increased by immediate operation, then the general rule of deferring all operation until arrival at a field hospital may surely be departed from, and advantage taken of the first halt to amputate the limb. The other plan has been tried, and with melancholy results; this of immediate treatment (under the circumstances men. tioned) has not yet had a trial.
CASEs $3,4,5$, and 6 were bayonet-wounds - two of them non-penetrating of the walls of the chest, and which soon got well ; the third peculiar from its situation-viz., in the right side of the fauces. The subject of it was leaning over in his saddle to make a cut, and received the bayonet in his mouth. The symptoms were only slight-some pain in swallowing, with slight swelling and tenderness of the neck.

The last case was a more serious one. The bayonet entered about two inches to the left of the navel and penetrated the peritoneum. Acute pain and collapse followed immediately, and some air seemed to have entered with the movements of respiration, for a few hours later the abdomen was tympanitic. Localised peritonitis followed, but the patient is now (A pril 23rd) convalescent.

CASE 7. - This is worth mention, as showing what terrible injuries a man will survive for a short time. The skull in this case, that of a non-commissioned officer, was cleft transversely across the vertex, the sides of the cleft being separated in the widest part by an eighth of an inch, and the cleft extending from ear to ear. In addition to this, another sabre-cut had raised the parietal portion of the temporal bone from its connexions. Yet this man lived until the fifth day, and never lost consciousness until shortly before death.

\section{9 解tirut}

\section{HOSPITAL PRACTICE,}

\section{BRITISH AND FOREIGN.}

Nulla autem est alia pro certo noscendi via, nisi quamplurimas et morborum et dissectionum historias, tum aliorum, tum proprias collectas habere, et inter se comparare.-Morgagri De Sed. et Caus. Morb, lib. í. Procmium.

\section{GUY'S HOSPITAL.}

CASES OF OVARIOTOMY IN WHICH ICE WAS LOCALLY APPLIED TO THE ABDOMEN AFTER THE OPERATION, FOLLOWED BY RECOVERY.

(Under the care of Mr. BRYANT.)

IN the following cases of ovariotomy ice was applied locally to the abdomen for several days after the operation, and the sponges employed were, as is usual in Mr. Bryant's practice, washed in iodine water (two drachms to a pint). In most of the cases it will be seen there was little or no elevation of temperature after the operation, and that in all a good recovery took place. There are good reasons for believing that the favourable results may be attributed to the treatment pursued, and that in the use of ice to the abdomen the surgeon has at his command a powerful means of preventing the elevation of temperature and of controlling it. Mr. Bryant says he thinks it probable this effect is brought about through the influence of the inorganic nerves.

CASE 1. Ovariotomy; application of ice to the abdomen recovery; highest temperature $100^{\circ}$. - Ruth $\mathrm{H}-$, aged twenty-two, was admitted Jan. 24th, 1877. Her general health was not good; had always been weakly. Married miscarried at three months two years and a half ago; one child born sixteen months since, but died when fourteen months old; another seven months' child was prematurely born three months ago.

Thirteen months previons to the birth of her first child (about two years and a half ago) she noticed that her abdomen began to swell on the right side, but she thought she was pregnant. In thirteen months a child was born yet the abdominal swelling did not quite disappear, but the swelling was centrally placed. She slowly increased in size up to the time of admission. Her last confinement was prematurely brought on. She lost flesh, and her legs swelled towards night-time. After her last confinement she had menstruated weekly, before that she was quite regular.

On admission there was great distension of abdomen, but more on right side than on left. Thrill on percussion all over tumour, which, however, was lost in the flanks. Tumour was generally soft, except about two inches above and a little to left of umbilicus, where there seemed to be solid growth. Dulness general, except at flanks and epi- 